\title{
CONSTRUCTION 3D BIM-BASED KNOWLEDGE MANAGEMENT SYSTEM: A CASE STUDY
}

\author{
Yu-Cheng LIN \\ Department of Civil Engineering, National Taipei University of Technology, \\ No. 1. Chung-Hsiao E. Rd., Sec. 3, Taipei, Taiwan, R.O.C.
}

Received 27 Sep 2011; accepted 07 May 2012

\begin{abstract}
Knowledge management (KM) is the organization, creation, sharing and flow of knowledge within organizations. Knowledge can be shared and reused among involved engineers and experts to improve a construction process and reduce the time and cost of solving problems. This paper proposes a new and practical methodology to capture and represent construction project knowledge by using a Building Information Modeling (BIM) approach. Using BIM approach, users can make visual knowledge management in the 3D Computer-aided Design (CAD) environment. This study addresses the application of knowledge management in the construction phase of construction projects and proposes a Construction BIM-based Knowledge Management (CBIMKM) system for general contractors. The CBIMKM is then applied in selected case studies of a construction building project in Taiwan to verify our proposed methodology and demonstrate the effectiveness of sharing knowledge in the 3D environment. By applying the BIM approach, all participants in a project can share and reuse explicit and tacit knowledge through the 3D CAD-based knowledge map. The combined results demonstrate that the CBIMKM system can be used as a visual 3D-based knowledge management platform by utilizing the BIM approach and web technology.
\end{abstract}

Keywords: construction knowledge management, BIM, building information modeling, project management, web-based information system.

Reference to this paper should be made as follows: Lin, Y.-C. 2014. Construction 3D BIM-based knowledge management system: a case study, Journal of Civil Engineering and Management 20(2): 186-200.

http://dx.doi.org/10.3846/13923730.2013.801887

\section{Introduction}

Information integration has been widely implemented in the construction projects industry in various forms (Kang et al. 2012). Knowledge content varies according to the organization seeking knowledge transfer. The capture of knowledge involves recording experiences in formats such as text, graphics, video and audio (Manavazhi 1995). Construction experience transfer is the use of knowledge gained in previous projects to maximize the achievement of current project objectives (Reuss, Tatum 1993). Useful knowledge can be recorded in different forms and media, such as in the minds of experts, or within documents, databases and intranets. Knowledge management (KM) is the collection of processes controlling the creation, storage, reuse, evaluation, and usage of experience in a particular situation or problem-solving context. $\mathrm{KM}$ is considered as the effective management of knowledge is critical to the continued advancement of the company (Park et al. 2010). Many construction enterprises and organizations engage in $\mathrm{KM}$ efforts to leverage experience within their organization, as well as externally with their shareholders and customers. KM in construction focuses on the acquisition and management of important issues and experience from participating engineers. Most engineers agreed that KM in construction projects is necessary and important with regard to construction management. Whatever successful and unsuccessful projects have been executed by general contractors, valuable knowledge and experience should be documented to identify best and worst company practices.

During the construction phase of projects, one of effective means of improving construction management is to share valued knowledge among engineers, which helps to prevent mistakes that have already been encountered in previous projects (Lin et al. 2006). Most construction companies in Taiwan recently had applied the commerce package for knowledge management. However, most knowledge management software/applications use textbased illustrations, but focus less on visual knowledge retrieval and sharing. In the construction phase of projects, there are many important relationships between the presentation and retrieval of knowledge and Computer-aided Design (CAD) in terms of knowledge management. Furthermore, it is not easy for engineers to understand the acquired knowledge directly without the $2 \mathrm{D}$ or $3 \mathrm{D}$ CAD illustrations when the knowledge is available to be shared. 
Engineers are easy to learn knowledge and experience regard to construction projects in the virtual 3D environment based on survey results. The Building Information Modeling (BIM) approach retains knowledge in a digital format, facilitating easy updating and transfer of knowledge in the 3D CAD environment. The main characteristics of BIM include illustrating 3D CAD-based presentations and keeping information in a digital format, and facilitate easy updating and transfer of information in the 3D CAD environment. Therefore, the primary purpose of this study is to acquire, manage, and reuse knowledge effectively for involved engineers, using the BIM approach integrated within the 3D CAD environment.

To enhance the effectiveness of visual KM applied in construction projects, this study develops a Construction BIM-based Knowledge Management (CBIMKM) system in the 3D CAD (Computer-aided Design) environment enabling engineers to share and reuse their knowledge and experience during the construction phase of a project. Senior engineers are thus invited to exchange and share their knowledge based on their own experience. In the case study of a Taiwan construction building project, the survey results indicated that the CBIMKM system integrated with BIM approach is a visual construction 3D-based knowledge management platform.

\section{Background}

In the construction industry, knowledge management is a discipline that promotes an integrated approach to the creation, capture, sharing and reuse of domain knowledge of a profession obtained from projects that have been previously undertaken. Numerous research efforts have focused on applications of knowledge management in construction. El-Diraby (2005) presented a distributed ontology architecture developed by rigorous knowledge acquisition and ontology development techniques for KM in the highway construction industry. Kivrak et al. (2008) used a survey to find out how tacit and explicit knowledge are captured, stored, shared, and used in forthcoming projects, as well as major drivers and barriers to knowledge management. A web-based prototype and system, named CAPRI.NET, was developed to facilitate the live capture and reuse of project knowledge in construction (Udeaja et al. 2008). A value engineering knowledge management system was developed to make the creativity phase more systematic, more organized, and more problem-focused (Zhang et al. 2009). A web-based collaborative knowledge management system was implemented to solve knowledge sharing problems within a construction company (Dave, Koskela 2009). The data mining approach was utilized to discover knowledge in construction enterprise performance record (Lee et al. 2008). The Knowledge map models were proposed and implemented to enhance knowledge management in construction projects (Tserng et al. 2010). Furthermore, a web-based knowledge management system was implemented to support effective information search and analysis, by enhancing communication and collaboration among researchers in the underground construction field (Forcada et al. 2010).
Building information modeling (BIM) is one of the most promising recent developments in the AEC industry (Azhar 2011). BIM which was introduced nearly ten years ago to provide an environment that any related information of 3D entity models could be retrieved during the project life cycle (Tse et al. 2005; Ding et al. 2012). BIM is believed to be essential in AEC to manage, share and exchange information among project stakeholders, such as architects, engineers, contractors, owners and subcontractors (Fu et al. 2006). BIM assists construction planners in making crucial decisions by enabling visualization of the details of the prospective work (Chau et al. 2004). Several definitions of BIM are proposed in prior research. According to the National Building Information Modeling Standard Committee, a building information model (BIM) is defined as "a digital representation of physical and functional characteristics of a facility. As such it serves as a shared knowledge resource for information about a facility forming a reliable basis for decisions during its lifecycle from inception onward" (National Building Information Modeling Standard 2011). BIM digitally contains precise geometry and relevant data needed to support the design, procurement, fabrication, and construction activities to describe 3D object-oriented CAD (Eastman et al. 2008). BIM is a new technology in the field of CAD, which contains not only geometric data, but also a great amount of engineering data through the lifecycle of a building (Xudong, Jie 2007). BIM is a new industry term referring to parametric $3 \mathrm{D}$ computer-aided design (CAD) technologies and processes in the AEC industry (Taylor, Bernstein 2009). BIM is a digital tool that supports continual updating and sharing of project design information (Gould, Joyce 2008). A Building Information Model is a computable representation of all building physical and functional characteristics and related lifecycle information, and is a repository of information for building owners and operators and used and maintained throughout the lifecycle of a building (Vanlande et al. 2008). A BIM system enables users to integrate and reuse building information and domain knowledge throughout the lifecycle of a building (Eddy, Bradley 2008). BIM is an additional model for engineering information database, storing all the architectural design with geometric information and the corresponding technical information of all the works (Ding et al. 2012). BIM supports the automatic evaluation of building design, rather than the manual, iterative and time-consuming evaluation of CAD drawings (Lee et al. 2012c). The main of characteristics is that the complete building model and all of its representations are included in the single BIM file. Furthermore, changes made in the BIM model will affect all related drawings and data automatically. BIM modeling enables the users to generate and update project documents automatically and building information data are attached to the elements (Eastman et al. 2008). Advanced analysis using the BIM modeling allows a wide range of analytical applications such as code checking, collision detection, energy efficiency analysis, structural analysis and simulation. 
Wide application of BIM is due to its various benefits throughout project design and planning, construction and facilities management. There are many benefits of BIM cited in the previous work in supporting decisions and improving processes throughout the lifecycle of a project (Eastman et al. 2008; Shen, Issa 2010; Manning, Messner 2008; Succar 2009; Becerik-Gerber, Rice 2010). Related to the design phase of a project, these benefits include parametric modeling, identification of design conflicts and analysis, green design, design simulation, cost estimation, and accurate geometric representation of all facilities (Ding et al. 2006; Li et al. 2006; Eastman et al. 2008; Shen, Issa 2010; Staub-French, Khanzode 2007: Manning, Messner 2008; Fox, Hietanen 2007; Shen et al. 2012; Lee et al. 2012a, b, c; Ren et al. 2012). During the construction phase, these benefits include less rework, reduction in requests for information and change orders, customer satisfaction through visualization, improved productivity in phasing and scheduling, faster and more effective construction management with easier information exchange, accurate cost estimation, and visualizing safety analysis (Eastman et al. 2008; Hardin 2009; Matta, Kam 2010; Azhar 2011; Zhou et al. 2012; Hartmann et al. 2012). During the operation phase, these benefits will include control of facilities management progress, integrated life-cycle data, rapid and accurate information of updating and changing activities, more effective facility management with easier information exchange (Eastman et al. 2008; Hardin 2009; StaubFrench, Khanzode 2007; Manning, Messner 2008; Underwood, Isikdag 2010; Laura et al. 2012; Rezgui et al. 2013). Regarding to education, there are many previous researches present the effectiveness of BIM as an integrated learning tool in construction education (Eastman et al. 2008; Becerik-Gerber, Kensek 2010; Sacks, Barak 2010).

Much previous research pertains to BIM issues in construction. Tse et al. (2005) presented the core barriers and recommends using BIM technology for construction industries. Vanlande et al. (2008) proposed an extension of BIM technology to manage information during the entire lifecycle of an AEC project. Goedert and Meadati (2008) extended BIM technology into the construction process to create a single repository of facility data for the owner. Kaner et al. (2008) illustrated how BIM can help managers of structural engineering firms avoid some of the pitfalls of replacing 2D CAD practices. Isikdag and Underwood (2010) proposed two design patterns as a foundation to formulate the design of information systems for BIM-based synchronous collaboration. Jeong et al. (2009) tested data exchanges between BIM tools using a small but complex building model. Dossick and Neff (2010) examined the use of BIM technologies for mechanical, electrical, plumbing, and life safety systems. Leite et al. (2011) evaluated the modeling effort associated with generating BIM at different level of detail (LoD) and the impact of LoD in a project. Jung and Joo (2011) proposed BIM framework for practical implementation. Redmond et al. (2012) explored information exchanges through Cloud BIM. Barlish and Sullivan (2012) develo- ped a methodology to analyze the benefits of BIM to quantify outcomes and impacts on project efficiency.

Although numerous information management systems have been developed for construction knowledge management application, most knowledge management systems exist for knowledge sharing only using textbased means for illustration of knowledge. In order to enhance engineers' ability to share and acquire project knowledge linking within a CAD-based environment, this study proposes a novel 3D BIM-based knowledge management system for construction projects using BIM approach.

\section{Methodology - BIM-based knowledge management}

Visualization Technology has been widely adopted in construction to facilitate construction planning (Liston et al. 1998), conflicts analysis (Zhang, Hu 2011), constructability reasoning (Golparvar-Fard et al. 2009) and site layout planning (Ma et al. 2005). Expression patterns of traditional information remain at the two dimensional (2D) level. However, people's perception of the building is three-dimensional. Performance of 2D graphics is limited, especially when dealing with the shape and size of the component as well as spatial relationships among the components. BIM is utilized as an efficient tool for visualizing construction progress and management. BIMbased visualization can express information more intuitively (Ding et al. 2012). It can realize real-time construction visualization. Besides, engineers can develop other management modules such as experience and knowledge management.

Engineers participating in projects act as knowledge workers facilitating the collection and management of knowledge between current and past projects. However, most of knowledge management is good at collecting and storing knowledge in the text-based environment. Communication and discussion may be enhanced effectively by visualization among all participants (Hajdasz 2008). The use of the 3D object models have essentially contributed to a shared understanding of intentions, needs and geometrical relations among actors representing different backgrounds, interests and positions (Moum 2010). Furthermore, 3D modeling makes the people to think accuracy and adequacy (Vainiunas et al. 2011). There are many relationships between knowledge and CAD in view of construction knowledge management. In order to assist engineers in sharing and acquiring project knowledge linked within a CAD-based environment, the main purpose for conducting this research is to develop CBIMKM system for involved engineers to enhance visual knowledge sharing and management efficiency in the 3D CAD environment. This study proposes a novel approach using 3D-based knowledge maps integrated with BIM to track and manage valued knowledge and experience. The main function of the BIM approach in this study is $3 \mathrm{D}$ CAD-based illustration and mapping of knowledge and experience. The 3D CAD-based knowledge maps using the BIM approach is applied in the study to keep knowledge information in a digital format, and facilitate updates and transfer of knowledge in the 3D CAD envi- 
ronment. Integrated with 3D CAD-based knowledge maps, users can get an overview of previous and current knowledge in selected projects and take appropriate advanced control and manage knowledge in construction projects. The primary purposes of this study are as follows: (1) assist all project participants in dynamically sharing and managing knowledge through the CBIMKM system to enhance knowledge sharing work; (2) develop a web-based KM system to improve the exchange of knowledge and tracking efficiency for participants and integrated with 3D CAD-based knowledge maps; and (3) develop the 3D CAD-based knowledge maps using BIM approach for illustrating knowledge, relating to objects easily and clearly in the 3D CAD environment.

Effective KM requires support from various participants, communication, and tools. The 3D-based knowledge maps using the BIM approach provides effective tools for KM in a digital and graphical form. Notably, 3D CAD-based knowledge maps stores the information for all knowledge management phases in the system such that all project participants can view the latest information via their own organizational perspective. Project participants can track and access the most recent knowledge regarding interesting topics or objects in a construction phase. Knowledge of topics or objects can be updated quickly and made available to each participant in the 3D CAD environment. This research is a pilot study to apply the CBIMKM system for knowledge management in building project in Taiwan (Fig. 1), analyzing and discussing whole processes of knowledge management, and KM implementation for construction projects. The processing and content of working construction knowledge could be modified according to the characteristics of construction projects. The results of an evaluation that involved a building project in Taiwan indicate that the CBIMKM system effectively supports the sharing of knowledge in the 3D CAD-based environment.
The case studies also emphasized that a CBIMKM system can provide a visual 3D-based knowledge management platform by utilizing the BIM approach and web technology.

\subsection{Concept of BIM-based knowledge management approach}

To capture the full benefit of BIM tools, general contractor in the project must coordinate and develop interoperable business practices. However, general contractor may have different interpretations toward the practice of using BIM tools. Differences in BIM adoption level across organizations in a project increase difficulties in utilizing BIM tools practices to support efficient use of knowledge management. This may explain difficulties identified in the adoption of BIM tools for knowledge management when compared to traditional KM system. In this paper we investigate and identify BIM-based practice in knowledge management. We examine how construction management involves with increasing use of BIM tools on knowledge management. BIM can be used by project participants during the construction phase, allowing project participants to track project updates and rapidly update digital records of work completed during the construction phase. Building information modeling has three main features. The first feature is that data and information of model can be stored in databases to facilitate collaboration. The second feature is that changes to these databases can be managed, such that a change in a database affects all other parts of models. The third feature is that information of model can be captured and preserved for reuse by adding industry-specific applications (Vanlande et al. 2008). In this study, the proposed CBIMKM system facilitates visual knowledge sharing and managing during the construction phase. The BIM approach

Level of Detail in BIM

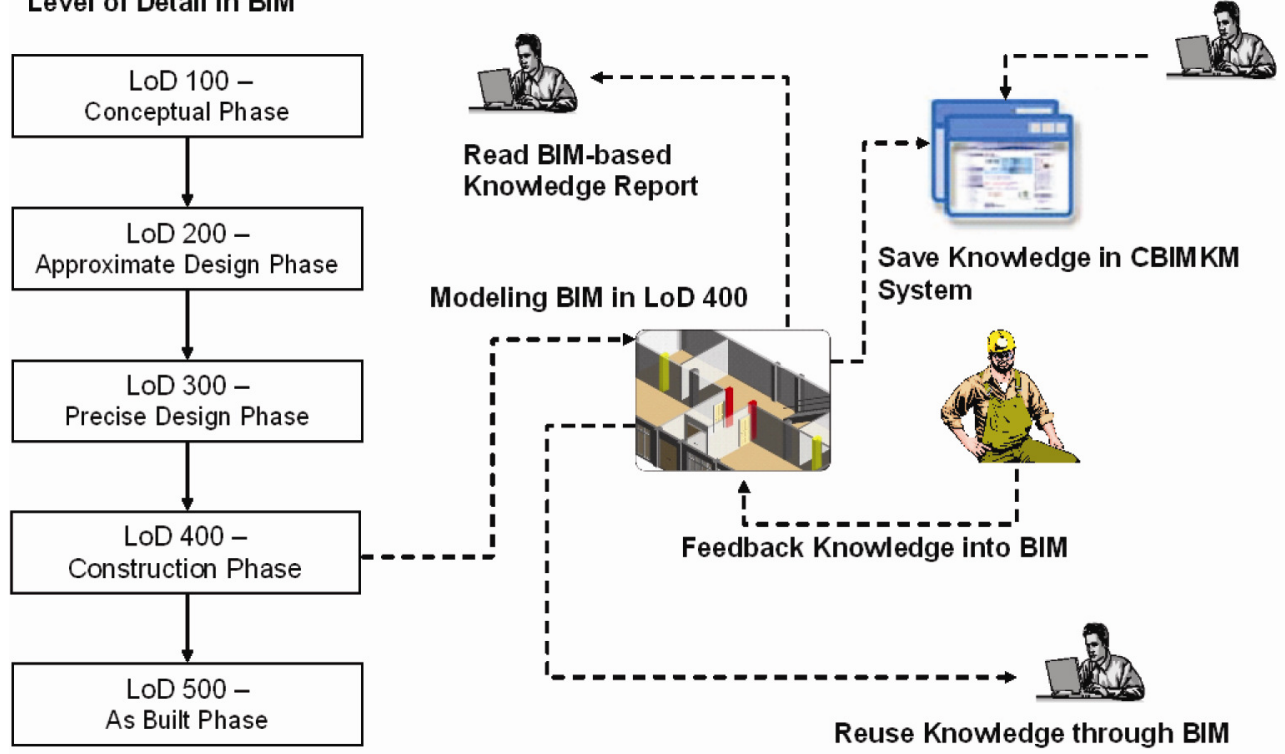

Fig. 1. The application of the BIM approach in construction knowledge management 


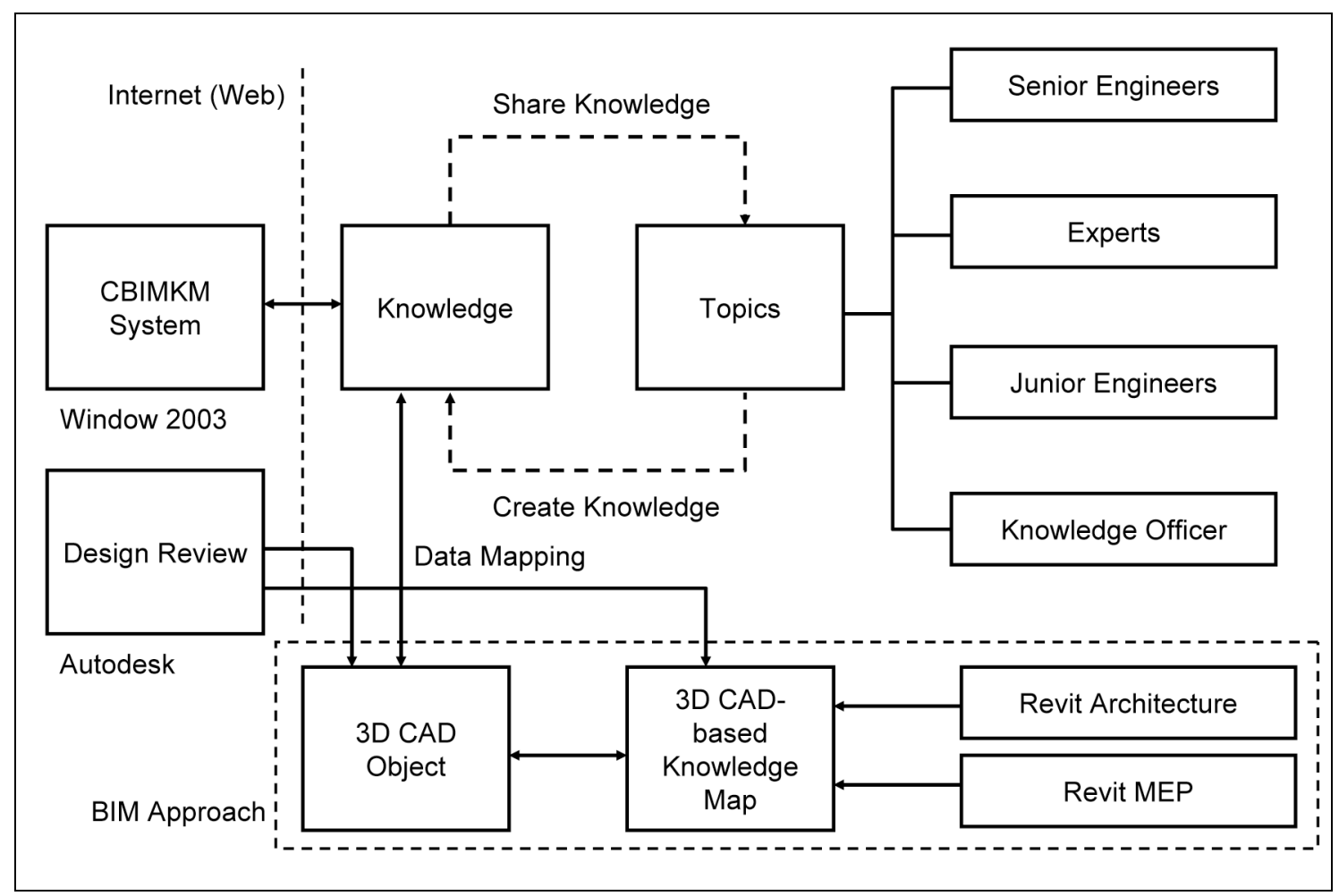

Fig. 2. The concept of the 3D CAD-based knowledge maps using BIM approach

stores the problems, solutions, experience, and comments, allowing all project participants to access the most up-to-date knowledge. Furthermore, BIM can also be modeling as an attitude, promoting the sharing of electronic information related to knowledge and its attributes with actives or CAD objects (Fig. 2). The primary advantages of 3D CAD-based knowledge maps using BIM approach are: (1) to provide a simple and clear representation of knowledge in the 3D CAD environment; (2) to effectively link knowledge to CAD-based graphic representations; (3) to extend knowledge relationships via both vertical and horizontal graphic representations; and (4) to provide statuses of acquired knowledge situations using different color presentation.

Most knowledge content in the construction project can be classified - as either tacit knowledge or explicit knowledge. Tacit knowledge is personal, context-specific knowledge that is difficult to formalize, record or articulate; it is stored in the heads of people (Hart 1992). The tacit experience is primarily developed through a process of trial and error in practice. Tacit knowledge that can be communicated directly and effectively is personal knowledge embedded in individual experience and shared and exchanged through direct, face-to-face contact (Tiwana 2000). In contrast, the acquisition of explicit knowledge is indirect: it must be decoded and re-coded into one's mental models, and is then internalized as tacit knowledge. Explicit knowledge can be codified and transmitted in a systematic and formal language. Explicit knowledge can be found in the documents of organizations, including reports, articles, manuals, patents, pictures, images, video, audio, software, and other forms. In the study, tacit knowledge refers to 'hard' information that is visibly or invisibly related to a part of a knowledge, including experience and know-how. Explicit knowledge is 'soft' information that enables or facilitates the execution of specific information, including contracting, drawing, solving problems or approving proposals. All participants in a project are responsible for providing the information/knowledge pertaining to their own domain. Any 3D CAD object whose integrated information/knowledge requirement has been noted will be classified to allow relevant experiences and processes to be recorded. Therefore, the information/knowledge associated with $3 \mathrm{D}$ CAD object can be referred to and reused in other projects.

Information and domain knowledge from all projects are divided and saved as "activity", "object", or "topic", for collection and management. The main advantage of BIM-based knowledge management is the ease with which information and knowledge can be understood and reapplied. Knowledge saved in the topic category includes both tacit and explicit knowledge. With respect to explicit knowledge, BIM-related information or knowledge normally includes original comments, reports, drawings, documents, and comments submitted by other participants. Information and knowledge that relates to the whole project and cannot be clearly classified into topic units is saved under "project" category of the activity. In contrast, tacit knowledge may include process records, problems faced, problems solved, expert suggestions, know-how, innovations and notes on experience. Information and knowledge is better saved in topic-based units to facilitate classification and searching by users.

The 3D CAD-based knowledge maps can be defined as a graphic representation of knowledge events linking 
relationships between 3D CAD objects and attributes of knowledge events. The BIM approach retains knowledge in a digital format, facilitating easy updating and transfer of knowledge in the 3D CAD environment. The 3D CADbased knowledge maps are designed to be easily integrated with knowledge events and 3D CAD objects. Assisted by the 3D BIM approach, knowledge in the 3D CAD-based knowledge maps can be identified, tracked, and managed, and problems encountered during construction projects can be solved. The most up-to-date knowledge and solutions can be acquired from participating engineers and then shared and saved as 3D CAD objects and future reference. The 3D CAD-based knowledge maps are constructed from variables that can be decomposed into $3 \mathrm{D}$ CAD objects and store the identified knowledge. Knowledge information stored in 3D CAD objects includes both facing problems and solutions. Problems faced may be knowledge topics, knowledge attributes, descriptions of problems, or knowledge attachments (e.g. documents, reports, drawings, and photographs). The proposed 3D CAD-based knowledge maps have eight components: event ID, event topic, event date, event description, event owner, event people, event attachments, and event history record (Fig. 3).

\subsection{Procedures for using the BIM-based knowledge management approach}

The procedures for BIM-based knowledge management are based on a knowledge management framework. The procedure consists of five phases: map creation; topic setup; sharing and discussion; acquisition; and update.

\section{Knowledge map creation phase}

The initial participant (engineer) may determine which projects, activities, and topics are suitable for knowledge sharing. Furthermore, the 3D CAD-based knowledge map must be created at the beginning of the construction phase. Usually, the 3D CAD-based models can be reused for knowledge management when the company applies BIM models for construction management, such as space conflict analysis.

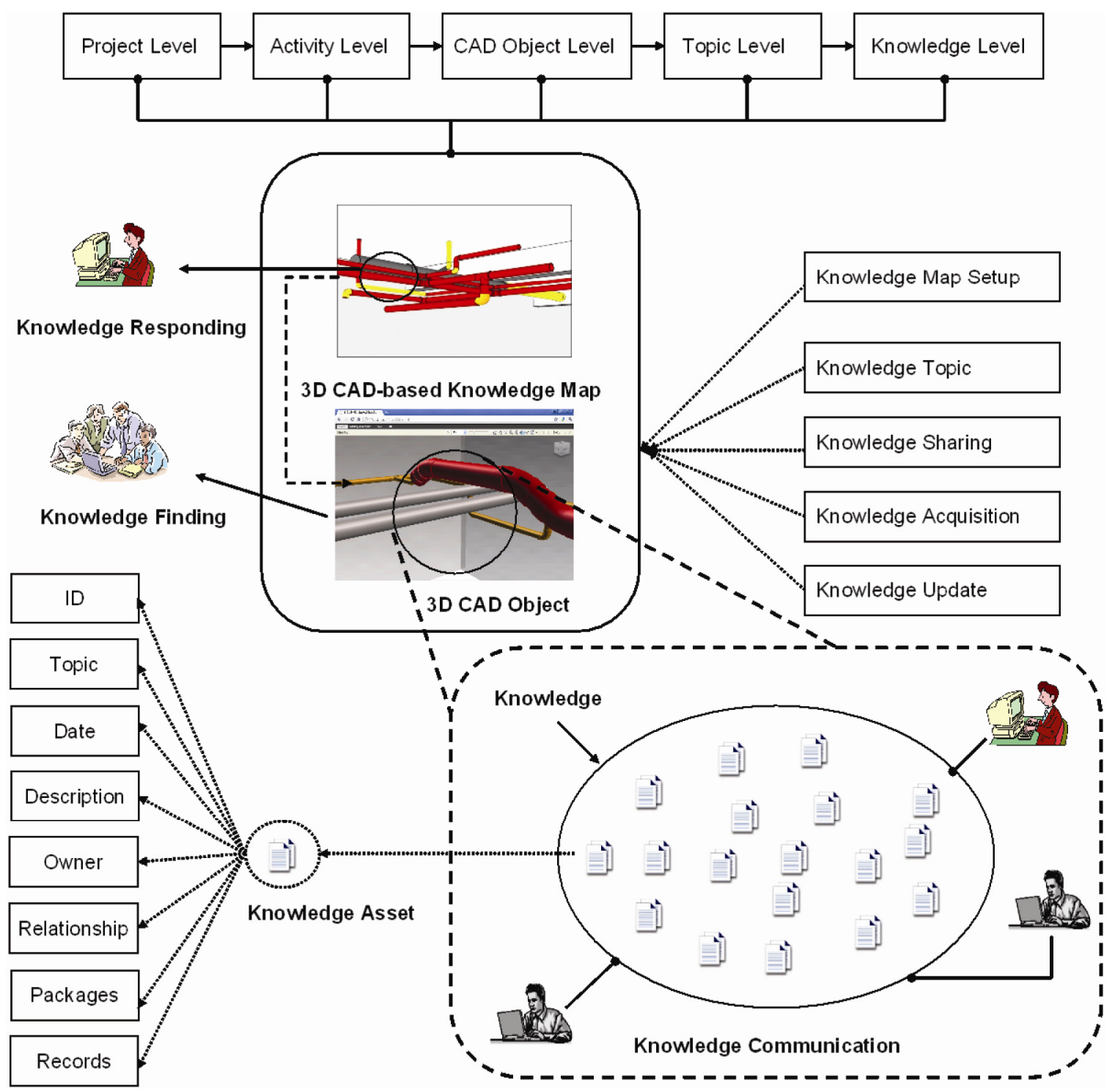

Fig. 3. The framework of 3D CAD-based knowledge maps approach 


\section{Knowledge topic setup phase}

The initial participant (engineer) may determine which projects, activities, and topics are suitable for knowledge sharing. Furthermore, the topic must be set up by the initial participant (engineer) at the beginning of the phase. Such information under knowledge topic includes determining the type of knowledge, 3D CAD objects, activities, and projects that should be assigned in association with the topic.

\section{Knowledge sharing and discussion phase}

After studying the published materials, all related or interested participants are invited to edit and submit their comments and knowledge regarding the topic. All explicit knowledge prepared by engineers must be digitized before submitting to the CBIMKM system. The digitization must be performed by assistants or engineers during this phase. All knowledge must be examined and confirmed before publishing. All interested engineers can discuss problems related to selected topics and 3D CAD objects, and seek responses from other engineers and managers through the CBIMKM system. Meanwhile, related participants can direct responses either to individual engineers or to all engineers.

\section{Knowledge acquisition phase}

After tacit and explicit knowledge are saved in the system, all knowledge can be referenced and reused by interested participants and engineers. Engineers can learn related experience and knowledge from the topics catalogue of the 3D CAD object, and engineers can access the topics catalogue for use in other similar projects.

\section{Knowledge update phase}

After applying tacit and explicit knowledge to other similar projects, the engineers resolve their problems and find new solutions related to those topics. Finally, the engineers note and submit the new tacit knowledge and experience, associated with the original knowledge. Furthermore, the knowledge is updated again because further feedback and updated knowledge is provided regarding the topics. After the approval process has been completed, the updated knowledge set is republished to authorized members.

\section{System implementation}

\subsection{System architecture}

The CBIMKM system provides a user-friendly portal for all project participants, which also serves as a real-time and on-line communication channel for knowledge management. All data are stored and classified using 3Dbased knowledge maps in the CBIMKM system. The CBIMKM system is a solution that uses a single, unified database linked to BIMs files with different levels of access granted to users based on their roles. Only authorized participants can access the 3D-based knowledge maps for knowledge entry and updates based on content relevant to the user's responsibilities in the project. When data or information is updated on the CBIMKM system, the server automatically sends e-mails and RSS to the project managers and engineers involved in the project.

The developed CBIMKM system runs on Microsoft Windows 2003 software with an Internet Information Server (IIS) as the web server. The CBIMKM system is developed using Java Server Pages (JSPs), which are easily incorporated with HTML and JavaScript technologies. The CBIMKM system server supports four distinct layers: interface, access, application and database layers (Fig. 4). Each layer has its own responsibilities. The interface layer defines administrative and end-user interfaces. Users can access information via web browsers such as Microsoft Internet Explorer or Google Chrome. Administrators control and manage information via the web browser or using a separate server interface. The access layer provides system security and restricted access, firewall services and system administration functions. The application layer defines various applications for analyzing and managing information. The database layer consists of a primary Microsoft SQL Server 2003 database. A firewall and virus scan can be used to protect the system database against intrusion. Users can utilize the BIMs in the CBIMKM system to request assistance or send a facing problem directly to the CBIMKM system to request further problem-related confirmation or contact.

In this study, the BIM is interpreted as an information model in the CBIMKM system. The primary purpose of this study is to extend BIM into the construction phase and to create a single repository of knowledge data for all project participants. Furthermore, the application of utilizing $\mathrm{BIMs}$ is to capture and store information or knowledge regarding to $3 \mathrm{D}$ object including facing problem description, knowledge, comments, and attaching documents in the CBIMKM system. Autodesk Revit Architecture and Revit MEP were used to model the 3D CAD-based knowledge maps and create BIM files. Autodesk Design Review was used to read BIM files for the 3D knowledge maps. The information integration with 3D CAD-based knowledge maps was achieved and programming using Autodesk Revit application programming interface (API) and Microsoft Visual Basic.Net (VB.Net) programming language. A program in $\mathrm{C}++$ was written to integrate the acquired data from different software programs. All the information and knowledge in BIM files can be exported to an ODBC database for connection with CBIMKM system. In order to enhance various knowledge illustrations in $3 \mathrm{D}$ CAD-based knowledge maps, the different color usages are applied in BIM module (Table 1).

\subsection{System modules}

All modules in the system are briefly outlined in the following descriptions.

\section{Authority management module}

The authority management module is an access control mechanism preventing unauthorized users from entering the system or retrieving sensitive knowledge 
Table 1. The application of color usage in BIM module

\begin{tabular}{c|l}
\hline Color Usage & \multicolumn{1}{c}{ Description } \\
\hline Yellow Color & To index there are knowledge sharing saving in the BIM objects and available for discussion in the system. \\
\hline Blue Color & To index there are knowledge sharing saving in the BIM objects and not available for discussion in the system. \\
\hline Red Color & $\begin{array}{l}\text { To index there are knowledge sharing saving in the BIM objects and wait for assistance in knowledge support in } \\
\text { the system. }\end{array}$ \\
\hline
\end{tabular}

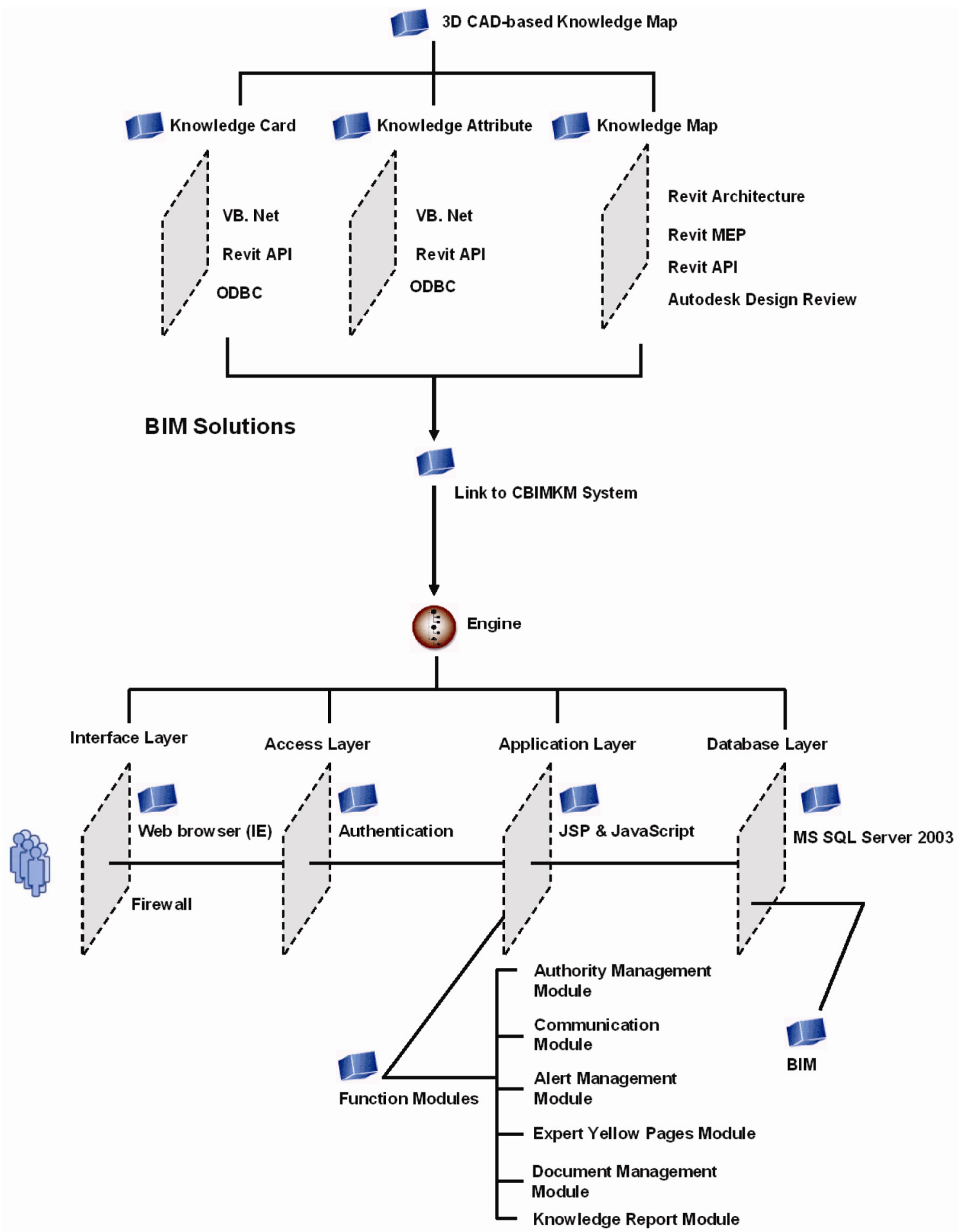

Fig. 4. System concept and framework 
information. The CBIMKM system requires all project participants to register by providing a unique User ID and password for authentication. As knowledge or attached documents required by different project participants vary, general contractors have different access rights and authorities than other parties.

\section{Communication module}

Through the module, project participants can edit their topic-related knowledge or experience regarding to the topics of selected 3D CAD objects. Generally, the participant may create a new topic or respond to the interesting topics for sharing their experience in the service. The edited knowledge will be saved in topics by categories associated with the relevant 3D CAD object, activity, and project. Also, attached documents and report files must be uploaded in PDF format, the standard file format. The communication module allows experts and engineers to share topic-based tacit knowledge via a discussion forum. Furthermore, engineers can refer to existing knowledge and solutions based on related problems or 3D CAD Objects when or even before a similar problem arises.

\section{Alert management module}

This module helps all project participants to set up an alert service for monitoring and managing knowledge via e-mail and RSS. Importantly, dates related to the notification of knowledge information are submitted or updated systematically; thus, project participants can determine who is invited to submit experience and knowledge. Furthermore, this module provides convenient access and a push-based function to help engineers respond to knowledge before progressed knowledge issues are tracked and others respond.

\section{Expert yellow pages module}

Expert Yellow Pages is a service that helps people find experts with relevant knowledge within the enterprise. It is just like the conventional Yellow Pages. All experts in the special domain or experience are stored in the system with reference to their specific area of expertise and professional trade. Users can use this service to find and contact experts whose expertise is needed in a project.

\section{Document management module}

The document management module allows users to download object-related electronic documents from the CBIMKM system. Additionally, the module provides knowledge document edition management function for knowledge sharing. This allows participants to manage, track, and organize knowledge-related files from a central location. This module also allows participants to determine when and by whom files have been accessed, downloaded, edited, or uploaded.

\section{Knowledge report module}

The knowledge report module allows users to easily access the summary knowledge to identify needs and ana- lyze knowledge. The knowledge report can be illustrated with 3D CAD objects and knowledge description and summary. Furthermore, all reports can be presented on the web or extracted to PDF format. This allows users to make and organize knowledge-related reports from a central location. This module also allows users to determine which type of report to use.

\section{Case study}

\subsection{Case study description}

In the following case, the general contractor has twenty years of specific experience in the construction building projects. Currently, the general contractor has construction projects mainly in Taiwan. Furthermore, the contractor hopes to develop the KM system to support knowledge sharing among junior and senior engineers. Therefore, the contractor announced that all engineers would be encouraged to use the CBIMKM system integrated with BIM approach to apply knowledge management to effectively manage acquired knowledge and experience from participating engineers in the 3D visual environment. Moreover, all engineers were encouraged to explore and edit their own experience from their recollections in the CBIMKM system. The case study was undertaken during a 6-month construction project. The construction project includes reinforced concrete structure buildings, underground parking and twelve floors of commercial building. The case study was presented at the middle phase during the construction phase. Figure 5 presents knowledge sharing in the 3D environment of the CBIMKM system.

The reason why this project was chosen was that the general contractor utilized BIM tools for the purpose of construction management during the construction phase. All BIM models were created and developed by the general contactor. The main benefits for general contractor included less rework, cost estimation, improved productivity and scheduling. Therefore, the general contractor decided to reuse those BIM models to enhance the application of knowledge and experience management. In other words, the BIM models were reused and applied for knowledge management. There were two full-time engineers with three years of BIM experience to handle the BIM-related knowledge management work in the project. The CBIMKM system was installed on the general contractor's main server during the test. A user guide was provided, and three CBIMKM system workshops were held to demonstrate how to use the CBIMKM system. The cost of installation and operation of the system is $\$ 120,000$ (including PC hardware and BIM software). All invited engineers originally used the web-based KM system using text-based illustrations in the company last five years. During the test period, they use the CBIMKM system just for the test project and web-based KM system using text-based illustrations in the company same time. During the case, invited engineers explained their experiences and comments based on the topic, and presented related information and documents. The initial engineer created topics regarding to the selected activity and 3D CAD object in the initial phase. After the topic was identified, the senior engineer was invited to share his knowledge and comments related to the 
topic via the system. The posted files included digital documents, photos and film files. The knowledge assistants assisted the senior engineer in digitizing the content, and created the 3D CAD object related to the topic using BIM approach. The other topics were communicated in the same manner. All engineers were required to submit knowledge, experience, and discussions regarding the topic via the CBIMKM system. Engineers read previous comments provided by other engineers, acquired the knowledge from previous knowledge, and submitted their discussions and comments via the CBIMKM system, which allowed other engineers and senior engineers to discuss their work. The comments provided by senior engineers included notes, actual problems/solutions, experience and suggestions. Finally, engineers communicated their problems and answers with senior engineers, posted their comments in the system and shared their case discussions with other engineers. Additionally, engineers had to submit their knowledge related to the topics of 3D CAD objects via the CBIMKM system. The senior engineers reviewed all questions/solutions and posted suggestions/comments to all interested engineers. Furthermore, all information was centralized and stored in the central database to prevent the collection of redundant data. The CBIMKM system automatically sends a message concerning updated content to engineers and senior engineers after saving updated content. In the beginning, most tacit knowledge to be extracted for reuse and storage may be available from the memories of experts and engineers. In a broader view, knowledge extraction may also include capturing knowledge from other sources such as problem-solution descriptions, suggestions, innovation, and collaboration.

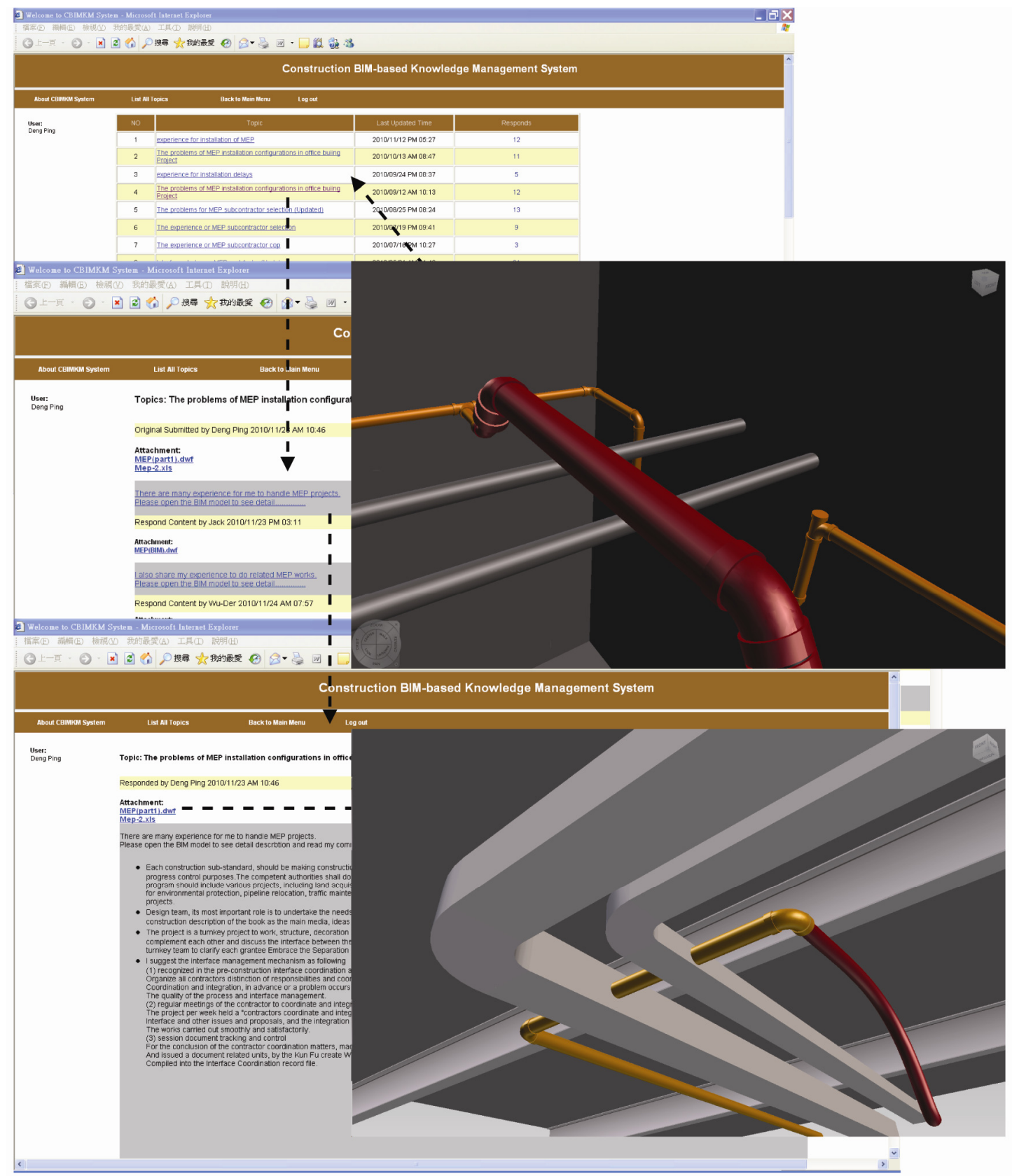

Fig. 5. Visual knowledge and experience sharing in the CBIMKM system 
In the case study, the senior engineer attempted to edit domain knowledge regarding the topic of "Interface facing problems and solutions in mechanical, electrical, and plumbing (MEP)". The learning experience under that topic included the interface problem-facing description in MEP, detailed situation description, and problem-solution explanations. The knowledge workers and senior engineer created the 3D CAD object and set-up topic and linked the object to activity in the CBIMKM system. After the topic was created under the "Install MEP equipment" activity, the three senior engineers were invited to edit their experiences with MEP construction and installation, then collected related information/ documentation and converted it into the appropriate digital format. The attached files included digital documents, video and photo files. The senior engineer then packaged them as a knowledge set for submission to be linked with $3 \mathrm{D}$ CAD object. All engineers were required to provide their own experiences regarding the tasks for which they were responsible. The engineer acquired knowledge from the project, and summarized his experience and domain knowledge in the 3D CAD object to store the problem's solution for use in other projects. Knowledge in the $3 \mathrm{D}$ CAD object included the knowledge topic, knowledge descriptions, knowledge attribute, knowledge packages such as related documents and photographs and video of processes, and expert suggestions such as notes, discussions and meeting records. Domain knowledge and experience was organized according to the attributes of the relevant 3D CAD object. When the submitted knowledge set was approved by knowledge management manager, the system illustrated the process automatically. Restated, users can find and read related knowledge directly simply by clicking these 3D CAD objects or knowledge topics. Finally, all submitted knowledge must be validated to perform well before the knowledge is published. All the validation needs to be performed with domain experts, knowledge workers and initial topic makers in the enterprise KM division.

One junior engineer utilized a keyword search to find the three senior engineers who owned similar previous experiences concerning MEP construction and installation. The junior engineer found the experts and retrieved, referred to and studied the knowledge set (including descriptions, digital videos, and documentation) provided by these senior engineers. The junior engineer began to apply and reuse the knowledge in his own project. Additionally, the junior engineer gave additional experienced feedback and offered his own experience to be reused when others face similar problems. Another senior engineer encountered two different problems in another project that had not happened before and were unavailable in the CBIMKM system. The senior requested suggestions and assistance from other senior engineers using the communication module in the CBIMKM system. Finally, the senior engineer solved his problem and shared the new solution with other senior engineers. Furthermore, the senior engineer created a new topic in the 3D CAD object and submits the obtained suggestion and experience to the new topic of the $3 \mathrm{D}$ CAD object. Moreover, the knowledge was updated later because further feedback and another solution to the same pro- blem were provided. The updated knowledge set was republished in the 3D CAD object of the CBIMKM system after the approval process was completed. A notice message was transmitted to authorized members.

\subsection{Evaluation}

The questionnaire results from the case study evaluation reveal that the CBIMKM system effectively shares knowledge and experience for construction projects. The verification test was performed by checking whether the CBIMKM system could perform tasks as specified in the system analysis and design. The validation test was undertaken by requesting selected case project practitioners to use the system, and the provide feedback by answering the questionnaire developed herein. The number of respondents was 13: two project managers with ten years of experience; five engineers with ten years of experience; five junior engineers with two years of experience; two knowledge workers with three years of experience, and one CKO (Chief Knowledge Officer) with ten years of experience. The CBIMKM system was demonstrated to the respondents, who were requested to express their opinions towards the system by completing the questionnaire. Table 2 shows the users' evaluation comments. Table 3 shows the results of the system testing.

Over 10 participants agreed that the CBIMKM system with BIM approach helps engineers view all knowledge in a 3D CAD environment. Questionnaire results indicate that the primary advantages of using the CBIMKM system are as follows: (1) to easily provide automatic corrections and notices when knowledge is updated on a current project (8 participants agreed); (2) to integrate with 3D CAD-based knowledge and knowledge management easily and effectively (10 participants agreed); and (3) to clearly identify available knowledge and experience when requested for a current project ( 8 participants agreed).

Questionnaire results indicate that the primary advantages of the application of BIM in 3D CAD-based knowledge maps are as follows: (1) to generate visual 3D object illustration with knowledge, thus identifying acquired knowledge and experience relevant to tasks and projects (11 participants agreed); (2) to provide clear 3D representations, thus identifying knowledge and experience relevant to an object or activity (10 participants agreed); (3) to view knowledge and information easily and effectively (11 participants agreed); and (4) to enable engineers to trace and manage acquired CADbased knowledge ( 7 participants agreed). Table 3 shows the evaluation result for BIM usage.

User feedback indicated that the primary barriers to using the CBIMKM system were as follows: (1) the limitation is the construction knowledge management is difficult to be implemented successfully using the BIM approach if the BIM models don't exist for the purpose of construction management during the construction phase; (2) high requirements of PC hardware regarding to using BIM software; (3) substantial amounts of time and assistance needed for engineers and managers to use BIM software to edit and update knowledge; (4) most users 
were unsatisfied with the high disconnection rate and slow Internet speed; (5) project participants often cannot easily use the visual $3 \mathrm{D}$ objects to edit knowledge when the original 3D BIM models were not developed or available during the construction phase; (6) most senior engineers cannot edit their knowledge without assistance in typing; (7) project participants may be confused about placing the knowledge into visual $3 \mathrm{D}$ object if the $3 \mathrm{D}$ CAD-based knowledge maps are not clearly known or are too complicated and, (8) unwillingness of participants to share their own knowledge and experience without enough incentives.

The following recommendations are based on received feedback: (1) Policy and strategy must be considered to encourage use of BIM because effective use requires that changes be made to almost every aspect of a firm's business; (2) Further effort is required to update knowledge information related to various $3 \mathrm{D}$ objects or activities in a project; (3) Initial case study results should be used to educate potential users about the adoption of BIM software, and additional staff training is needed.

Table 2. Users evaluation comments

\begin{tabular}{cl}
\hline Comment & \multicolumn{1}{c}{ User Comment } \\
\hline 1 & $\begin{array}{l}\text { I especially like to use the BIM model to illustrate } \\
\text { knowledge that I want to explain and share stored } \\
\text { in CAD. }\end{array}$ \\
\hline 2 & $\begin{array}{l}\text { The BIM is very helpful because I can understand } \\
\text { and learn easily and effectively the attribute of } \\
\text { knowledge related to a CAD object. }\end{array}$ \\
\hline 3 & $\begin{array}{l}\text { That will be great if the BIM application can be } \\
\text { edited and accessed directly in the web environ- } \\
\text { ment. That will be helpful for knowledge manage- } \\
\text { ment. }\end{array}$ \\
\hline 4 & $\begin{array}{l}\text { I am used to using the traditional AutoCAD soft- } \\
\text { ware. It is hard for me to use the CAD model in the } \\
\text { 3D environment. }\end{array}$
\end{tabular}

\begin{tabular}{cl}
\hline 5 & $\begin{array}{l}\text { I learn much in a 3D CAD-based knowledge } \\
\text { management environment. Actually, it should be } \\
\text { helpful and important for junior engineers in e- } \\
\text { learning. }\end{array}$ \\
\hline 6 & $\begin{array}{l}\text { It is not easy for me to learn BIM software in the } \\
\text { beginning. Also, it takes time for me to be used to } \\
\text { applying KM in a 3D environment. }\end{array}$ \\
7 & $\begin{array}{l}\text { The main problem I have in sharing knowledge } \\
\text { with others is that I am too busy to have time to } \\
\text { edit my knowledge and experience when I go back } \\
\text { to site office. }\end{array}$ \\
\hline 8 & $\begin{array}{l}\text { The application of KM using 3D CAD map is great } \\
\text { idea and useful method for knowledge manage- } \\
\text { ment in construction. However, most senior engi- } \\
\text { neers have problems learning the BIM software in } \\
\text { the beginning. }\end{array}$ \\
\hline 9 & $\begin{array}{l}\text { The explanations were sometimes difficult to } \\
\text { understand. With the assistance of 3D CAD, the } \\
\text { knowledge and experience will be easy for junior } \\
\text { engineers to understand and learn. }\end{array}$ \\
\hline 10 & $\begin{array}{l}\text { The system is very helpful because I can share and } \\
\text { reuse other participants' comments and experience. }\end{array}$ \\
\hline
\end{tabular}

Table 3. System evaluation results

\begin{tabular}{lc}
\hline \multicolumn{1}{c}{ Functionality of system } & Mean Score \\
\hline Ease of Knowledge Sharing & 4.5 \\
Ease of Knowledge Illustration & 4.4 \\
Applicability to Construction KM & 4.8 \\
\hline \multicolumn{1}{c}{ Use of system } & Mean Score \\
\hline Ease of Use & 4.6 \\
User Interface & 4.5 \\
Information Sufficiency & 4.6 \\
System Usefulness & 4.3 \\
\hline \multicolumn{1}{c}{ Capability of system } & Mean Score \\
\hline Reduces Unnecessary Costs & 4.1 \\
Reduces Rate of Mistake Occurrence & 4.3 \\
Ease of Finding Knowledge Location & 4.7 \\
Improves Knowledge Communication & 4.4 \\
Enhances Knowledge Sharing & 4.5 \\
Enhances Learning Performance & 4.2 \\
Improves Experience Management & 4.7 \\
\hline
\end{tabular}

Note: the mean score is calculated from respondents' feedback on Five-scale questionnaire: 1 (Strongly Disagree), 2, 3, 4 and 5 (Strongly Agree).

\section{Conclusion}

To enhance construction KM, this study presented and developed the CBIMKM system as a visual platform for enhancing knowledge and experience exchange among participants. The CBIMKM system with BIM approach illustrates visual knowledge with problem descriptions and solutions in the $3 \mathrm{D}$ CAD environment. BIM is a highly promising means of enhancing $\mathrm{KM}$ during the construction phase of a project. The BIM approach generates 3D knowledge map from identified knowledge, thus identifying valued knowledge and experience relevant to topics and activities. Additionally, BIM provides 3D knowledge object and illustration when knowledge and experience are available. The CBIMKM system collects specific problem solutions, and supports all knowledge and experience across projects. Overall, field test results indicate that the CBIMKM system is an effective and simple platform for construction KM. Case study results demonstrate the effectiveness of a CBIMKM-like system for KM by incorporating BIM and web technologies in the construction phase. The concept of a CBIMKM system is presented, and a system for use as a knowledge-sharing platform in construction projects is presented. The application of a 3D knowledge map in the BIM approach mainly allows project assistants to find the needed knowledge easily and effectively. Although effort is required to update knowledge for various problems and solutions, the proposed CBIMKM system benefits KM by (1) providing an effective and efficient platform to assist $\mathrm{KM}$ tasks in a 3D CAD environment, (2) facilitating implementation of a web-based KM system for construction projects, (3) enabling users to find the needed knowledge and experience from experienced participants.

The application of the CBIMKM system framework in the context of $\mathrm{KM}$ is foreseen to overcome many technological barriers by re-using much of the standardization and research work done in the BIM and $\mathrm{A} / \mathrm{E} / \mathrm{C}$ 
sector. Management information such as domain knowledge, know-how, and experience will be integrated via 3D model so as to provide useful information for project participants. The BIM models were proven to be good tools for KM in A/E/C projects. Findings from this study will enhance BIM-based research and development to better facilitate the adoption of the technologies, leading to better knowledge illustration and visual $\mathrm{KM}$ in the construction phase. Future work may involve strategy of the implementation and further studies to expand the mechanism and technical requirements. More case studies are also needed for a comprehensive assessment of BIMbased applications for other types of construction KM. In these phases other challenges are expected to occur, mainly because the level of detail increases significantly, and because of the need to manage more complex contracts and contents among more participants.

\section{Acknowledgement}

The authors would like to acknowledge the National Science Council, Taiwan, for financially supporting this work under contract number NSC 99-2221-E-027-093 and express our appreciation to the F-D Construction Inc for assistance in the system design and interviews, and to the experts and engineers of the owner of the project for providing useful data, valuable information, and helpful comments during system design and development.

\section{References}

Azhar, S. 2011. Building Information Modeling (BIM): trends, benefits, risks, and challenges for the AEC industry, Leadership and Management in Engineering 11(3): 241-252. http://dx.doi.org/10.1061/(ASCE)LM.1943-5630.0000127

Barlish, K.; Sullivan, K. 2012. How to measure the benefits of BIM-A case study approach, Automation in Construction 24: 605-613. http://dx.doi.org/10.1016/j.autcon.2012.02.008

Becerik-Gerber, B.; Kensek, K. 2010. Building information modeling in architecture, engineering, and construction: emerging research directions and trends, Journal of Professional Issues in Engineering Education and Practice 136(3): 139-147. http://dx.doi.org/10.1061/(ASCE)EI.1943-5541.0000023

Becerik-Gerber, B.; Rice, S. 2010. The perceived value of building information modeling in the US building industry, Electronic Journal of Information Technology in Construction (ITCON) [online] 15: 185-201. [cited 20 May 2011]. Available from Internet: http://www.itcon.org

Chau, K.; Anson, M.; Zhang, J. 2004. Four-dimensional visualization of construction scheduling and site utilization, Journal of Construction Engineering and Management 130(4): 598-606. http://dx.doi.org/10.1061/(ASCE)07339364(2004)130: 4(598)

Dave, B.; Koskela, L. 2009. Collaborative knowledge management - a construction case study, Automation in Construction 18(7): 894-902. http://dx.doi.org/10.1016/j.autcon.2009.03.015

Ding, L. Y.; Zhou, Y.; Luo, H. B.; Wu, X. G. 2012. Using nD technology to develop an integrated construction management system for city rail transit construction, Automation in Construction 21(7): 64-73.

http://dx.doi.org/10.1016/j.autcon.2011.05.013
Ding, L.; Drogemuller, R.; Rosenman, M.; Marchant, D.; Gero, J. 2006. Automating code checking for building designs. Clients driving construction innovation: moving ideas into practice. CRC for Construction Innovation, Brisbane, Australia, 113-126.

Dossick, C. S.; Neff, G. 2010. Organizational divisions in BIMenabled commercial construction, Journal of Construction Engineering and Management 136(4): 459-467. http://dx.doi.org/10.1061/(ASCE)CO.1943-7862.0000109

Eastman, C.; Teicholz, P.; Sacks, R.; Liston, K. 2008. BIM handbook: a guide to building information modeling for owners, managers, designers, engineers and contractors. Hoboken, NJ: Wiley. 490 p. http://dx.doi.org/10.1002/9780470261309

Eddy, K.; Bradley, N. 2008. Green BIM: successful sustainable design with building information modeling. Hoboken, NJ: Wiley.

El-Diraby, T. E. 2005. Distribute ontology architecture for knowledge management in highway construction, Journal of Construction Engineering and Management 131(5): 591-603. http://dx.doi.org/10.1061/(ASCE)0733-9364 (2005)131:5(591)

Forcada, N.; Casals, M.; Fuertes, A.; Gangolells, M.; Roca, X. 2010. A web-based system for sharing and disseminating research results: the underground construction case study, Automation in Construction 19(4): 458-474. http://dx.doi.org/10.1016/j.autcon.2009.12.018

Fox, S.; Hietanen, J. 2007. Interorganizational use of building information models: potential for automational informational and transformational effects, Construction Management and Economics 25(3): 289-296. http://dx.doi.org/10.1080/01446190600892995

Fu, C.; Aouad, G.; Lee, A.; Ponting, A.; Wu, S. 2006. IFC model viewer to support $\mathrm{nD}$ model application, Automation in Construction 15(2):178-185. http://dx.doi.org/10.1016/j.autcon.2005.04.002

Goedert, J. D.; Meadati, A. G. F. 2008. Integrating construction process documentation into building information modeling, Journal of Construction Engineering and Management 134(7): 509-516. http://dx.doi.org/10.1061/(ASCE)0733-9364(2008)134: 7(509)

Golparvar-Fard, M.; Peña-Mora, F.; Arboleda, C.; Lee, S. 2009. Visualization of construction progress monitoring with 4D simulation model overlaid on time-lapsed photographs, Journal of Computing in Civil Engineering 11: 391-404. http://dx.doi.org/10.1061/(ASCE)0887-3801(2009)23: 6(391)

Gould, F.; Joyce, N. 2008. Construction project management. $3^{\text {rd }}$ ed. Prentice Hall. 357 p.

Hajdasz, M. 2008. Visualizing simulated monolithic construction processes, Journal of Civil Engineering and Management 14(4): 295-306. http://dx.doi.org/10.3846/1392-3730.2008.14.29

Hardin, B. 2009. BIM and construction management: proven tools, methods, and workflows. New Jersey: John Wiley \& Sons. 364 p.

Hart, A. 1992. Knowledge acquisition for expert systems. $2^{\text {nd }}$ ed. New York: McGraw-Hill. 196 p.

Hartmann, T.; Meerveld, H. V.; Vossebeld, N.; Adriaanse, A. 2012. Aligning building information model tools and construction management methods, Automation in Construction 22: 605-613. http://dx.doi.org/10.1016/j.autcon.2011.12.011 
Isikdag, U.; Underwood, J. 2010. Two design patterns for facilitating building information model-based synchronous collaboration, Automation in Construction 19(5): 544-553.

Jeong, Y. S.; Eastman, C. M.; Kaner, R. S. 2009. Benchmark test for BIM data exchanges of precast concrete, Automation in Construction 18(4): 469-484. http://dx.doi.org/10.1016/j.autcon.2008.11.001

Jung, Y.; Joo, M. 2011. Building information modelling (BIM) framework for practical implementation, Automation in Construction 20(2): 126-133. http://dx.doi.org/10.1016/j.autcon.2010.09.010

Kaner, I.; Sacks, R.; Kassian, W.; Quitt, T. 2008. Case studies of BIM adoption for precast concrete design by mid-sized structural engineering firms, Journal of Information Technology in Construction 13: 303-323.

Kang, Y.; O'Brien, W. J.; O'Connor, J. T. 2012. Analysis of information integration benefit drivers and implementation hindrances, Automation in Construction 22: 102-111. http://dx.doi.org/10.1016/j.autcon.2011.09.003

Kivrak, S.; Arslan, G.; Dikmen, I.; Birgonul, M. T. 2008. Capturing knowledge in construction projects: knowledge platform for contractors, Journal of Management in Engineering 24(2): 87-95.

http://dx.doi.org/10.1061/(ASCE)0742-597X(2008)24: 2(87)

Laura, K.; Nan, L.; Burcin, B. G. 2012. Imaged-based verification of as-built documentation of operational buildings, Automation in Construction 21(1): 161-171.

Lee, G.; Park, H. K.; Won, J. 2012a. D ${ }^{3}$ City project - economic impact of BIM-assisted design validation, Automation in Construction 22: 577-586. http://dx.doi.org/10.1016/j.autcon.2011.12.003

Lee, J. K.; Lee, J.; Jeong, Y.-S.; Sheward, H.; Sanguinetti, P.; Abdelmohsen, S.; Eastman, C. M. 2012c. Development of space database for automated building design review systems, Automation in Construction 24: 203-212. http://dx.doi.org/10.1016/j.autcon.2012.03.002

Lee, J. R.; Hsueh, S. L.; Tseng, H. P. 2008. Utilizing data mining to discover knowledge in construction enterprise performance records, Journal of Civil Engineering and Management 14(2): 79-84. http://dx.doi.org/10.3846/1392-3730.2008.14.2

Lee, S. I.; Bae, J. S.; Cho, Y. S. 2012b. Efficiency analysis of set-based design with structural building information modeling (S-BIM) on high-rise building structures, Automation in Construction 23: 20-32.

http://dx.doi.org/10.1016/j.autcon.2011.12.008

Leite, F.; Akcamete, A.; Akinci, B.; Atasoy, G.; Kiziltas, S. 2011. Analysis of modeling effort and impact of different levels of detail in building information models, Automation in Construction 20(5): 601-609. http://dx.doi.org/10.1016/j.autcon.2010.11.027

Li, G.; Ding, L.; Wang, J. 2006. Construction project control in virtual reality: a case study, Journal of Applied Science 3(13): 2724-2732.

Lin, Y. C.; Wang, L. C.; Tserng, H. P. 2006. Enhancing knowledge exchange through web map-based knowledge management system in construction: lessons learned in Taiwan, Automation in Construction 15(6): 693-705. http://dx.doi.org/10.1016/j.autcon.2005.09.006

Liston, K. M.; Fischer, M.; Kunz, J. 1998. 4D annotator: a visual decision support tool for construction planners, Journal of Computing in Civil Engineering, 330-341.
Ma, Z. Y.; Shen, Q. P.; Zhang, J. P. 2005. Application of 4D for dynamic site layout and management of construction projects, Automation in Construction 14(3): 369-381. http://dx.doi.org/10.1016/j.autcon.2004.08.011

Manavazhi, M. R. 1995. Case-based reasoning and hypermedia: enabling technologies for construction experience transfer. Technical Report \# 102, Center for Integrated Facility Engineering, Stanford University, CA, August 1995.

Manning, R.; Messner, J. 2008. Case studies in BIM implementation for programming of healthcare facilities, Electronic Journal of Information Technology in Construction (ITCON) [online] 13: 446-457. [cited 27 March 2011]. Available from Internet: http://www.itcon.org

Matta, C.; Kam, C. 2010. The GSA'sBIM pilot program [online]. Presentation by GSA PBS Office of the Chief Architect [cited 21 March 2010]. Available from Internet: http://bim.arch.gatech.edu/data/reference/gsaBIM.pdf

Moum, A. 2010. Design team stories exploring interdisciplinary use of 3D object models in practice, Automation in Construction 19(5): 554-569.

http://dx.doi.org/10.1016/j.autcon.2009.11.007

NBIMS. 2007. National building information modeling standard (NBIMS), overview, principles and methodologies, version 1.0 - Part 1 [online], [cited 19 September 2011]. Available from Internet: http://www.wbdg.org/pdfs/ NBIMSv1_p1.pdf 8

Park, M.; Lee, H. S.; Kwon, S. 2010. Construction knowledge evaluation using expert index, Journal of Civil Engineering and Management 16(3): 401-411. http://dx.doi.org/10.3846/jcem.2010.46

Redmond, A.; Hore, A.; Alshawi, M.; West, R. 2012. Exploring how information exchanges can be enhanced through Cloud BIM, Automation in Construction 24: 175-183. http://dx.doi.org/10.1016/j.autcon.2012.02.003

Ren, Y.; Skibniewski, M. J.; Jiang, S. 2012. Building information modeling integrated with electronic commerce material procurement and supplier performance management system, Journal of Civil Engineering and Management 18(5): 642-654. http://dx.doi.org/10.3846/13923730.2012.719835

Reuss, M. C.; Tatum, C. B. 1993. Requirements and tools for transferring construction experience between projects. Technical Report \# 78, Center for Integrated Facility Engineering, Stanford University, CA, Feb 1993.

Rezgui, Y.; Beach, T.; Rana, O. 2013. A governance approach for BIM management across lifecycle and supply chains using mixed-modes of information delivery, Journal of Civil Engineering and Management 12(9): 239-258. http://dx.doi.org/10.3846/13923730.2012.760480

Sacks, R.; Barak, R. 2010. Teaching building information modeling as an integral part of freshman year civil engineering education, Journal of Professional Issues in Engineering Education and Practice 136(1): 30-38. http://dx.doi.org/10.1061/(ASCE)EI.1943-5541.0000003

Shen, W.; Shen, Q.; Sun, Q. 2012. Building information modeling-based user activity simulation and evaluation method for improving designer-user communications, Automation in Construction 21: 148-160. http://dx.doi.org/10.1016/j.autcon.2011.05.022

Shen, Z.; Issa, R. 2010. Quantitative evaluation of the BIM assisted construction detailed cost estimates, Electronic Journal of Information Technology in Construction (ITCON) [online] 15: 234-257. [cited 22 May 2011]. Available from Internet: http://www.itcon.org 
Staub-French, S.; Khanzode, A. 2007. 3D and 4D modeling for design and construction coordination: issues and lessons learned, Electronic Journal of Information Technology in Construction (ITCON) [online] 12: 381-407 [cited 5 June 2011]. Available from Internet: http://www.itcon.org

Succar, B. 2009. Building information modelling framework: a research and delivery foundation for industry stakeholders, Automation in Construction 18(3): 357-375. http://dx.doi.org/10.1016/j.autcon.2008.10.003

Taylor, J. E.; Bernstein, P. G. 2009. Paradigm trajectories of building information modeling practice in project networks, Journal of Management in Engineering 25(2): 69-76. http://dx.doi.org/10.1061/(ASCE)0742-597X (2009)25:2(69)

Tiwana, A. 2000. The knowledge management toolkit - practical techniques for building a knowledge management system. New Jersey: Prentice-Hall.

Tse, T. K.; Wong, K. A.; Wong, K. F. 2005. The utilisation of building information models in $\mathrm{nD}$ modelling: a study of data interfacing and adoption barriers, Electronic Journal of Information Technology in Construction (ITCON) [online] 10: 85-110. [cited16 May 2011]. Available from Internet: http://www.itcon.org

Tserng, H. P.; Yin, S. Y.-L.; Lee, M. H. 2010. The use of knowledge map model in construction industry, Journal of Civil Engineering and Management 16(3): 332-344. http://dx.doi.org/10.3846/jcem.2010.38

Udeaja, C. E.; Kamara, J. M.; Carrillo, P. M.; Anumba, C. J.; Bouchlaghem, N.; Tan, H. C. 2008. A web-based prototype for live capture and reuse of construction project knowledge, Automation in Construction 17(7): 839-851. http://dx.doi.org/10.1016/j.autcon.2008.02.009

Underwood, J.; Isikdag, U. 2010. Handbook of research on building information modeling and construction informatics: concepts and technologies. IGI Global. 715 p.

Vainiunas, P.; Popovas, V.; Jarmolajev, A. 2011. Non-linear 3D modelling of RC slab punching shear failure, Journal of Civil Engineering and Management 10(4): 311-316. http://dx.doi.org/10.1080/13923730.2004.9636324

Vanlande, R.; Nicolle, C.; Cruz, C. 2008. IFC and building lifecycle management, Automation in Construction 134(7): 70-78. http://dx.doi.org/10.1016/j.autcon.2008.05.001

Xudong, Z.; Jie, T. 2007. Building information modeling based on intelligent parametric technology, Frontiers of Architecture and Civil Engineering in China 1(3): 367-370. http://dx.doi.org/10.1007/s11709-007-0049-4

Zhang, J. P.; Hu, Z. Z. 2011. BIM- and 4D-based integrated solution of analysis and management for conflicts and structural safety problems during construction: 1. Principles and methodologies original research article, Automation in Construction 20(2): 155-166. http://dx.doi.org/10.1016/j.autcon.2010.09.013

Zhang, X.; Mao, X.; AbouRizk, S. M. 2009. Developing a knowledge management system for improved value engineering practices in the construction industry, Automation in Construction 18(6): 777-789. http://dx.doi.org/10.1016/j.autcon.2009.03.004

Zhou, W.; Whyte, J.; Sacks, R. 2012. Construction safety and digital design: a review, Automation in Construction 22: 102-111. http://dx.doi.org/10.1016/j.autcon.2011.07.005

Yu-Cheng LIN. Associate Professor of Construction Engineering and Management at the Department of Civil Engineering of the National Taipei University of Technology. He received the MS degree in the construction management program of Civil Engineering from the Polytechnic University, New York, USA and received PhD degree from the National Taiwan University in Taiwan (2004). He has published several articles and papers on the role of academic support service in computer-based construction project management. His current research interests include construction knowledge management, project interface management, building information modeling, web-based project management system, IT technology application, automation, E-Commerce related topics. 